\title{
The Varieties of Conceptualizing Culture: A Case of Jewish Israelis
}

\author{
Gabriel Bukobza \\ Tel Aviv University \\ Israel
}

Cultural Episteme (CE) is a concept meant to represent a mental framework that systematically organizes cultural knowledge and choice. In the present study $\mathbf{8 0}$ Jewish Israeli participants from four adult age groups were interviewed regarding two cultural dilemmas which probed their CEs. Interpretation of the interviews supported the existence of four distinct, self-consistent CEs. These were named Monoculturalism, Pluralistic Relativism, Dialectic Multiculturalism, and Integral Uniculturalism. Distribution of the various CEs varied by age. The significance of the CE is discussed in terms of cultural orientations, identities, and development, and in the context of multicultural environments.

Culture as System of Knowledge and Choice
Cultural Epistemes
Method
Results
Discussion
Recommendations for Further Study
References
Appendix

In order to perceive, understand, and react well to cultural knowledge, individuals construe mental frameworks which organize that knowledge and the meaning it entails (Bruner, 2008). A well-structured framework can accommodate for the rich and dynamic nature of cultural phenomena and provide individuals a manner by which knowledge is systematically ordered, experience meaningfully made, and decisions sensibly taken. The importance of the framework is further evident in multicultural environments and in circumstances of colonization, migration, and international contact characterized by a high degree of cultural epistemological diversity (Siegel, 2006). Though diversity allows for enriching and exciting experiences, it may additionally generate feelings of confusion, anxiety, fear, and stress. A complex mental framework could encompass the plurality found in such cultural settings and once again assist the individual in adapting well to the rich and dynamic cultural environment. The purpose of the 
present research was to explore different mental frameworks that are being used by individuals in cultural contexts.

The mental framework will presently be referred to as the Cultural Episteme (CE) of a person. The term "episteme" was coined by Foucault (1970/1966) who suggested that it may be conceived of as a set of regulations that unite the discursive practices that generate scientific and cultural knowledge. In the present investigation the CE is proposed to consist of a set of principles of order, which govern the cultural knowledge contents that a person possesses or encounters (Banks, 1993; Kelley, 1955; Medin, 1989). It is hypothesized that different types of CEs would be found in individuals belonging to the same cultural group.

The CE is related to concepts such as interpretive frames, cultural schemes, and cultural identities that process social information following an activation by cultural cues (Benet-Martinez, Lee, \& Leu, 2006; Hong, Morris, Chiu, \& Benet-Martinez, 2000). The added value of the epistemological approach is that it denotes the basic underlying rules that all types of frameworks follow when they process cultural knowledge and could therefore suggest a parsimonious explanation for their different manifestations.

The present study was carried in Israel with a sample of Jewish-Israeli participants. Israeli society is composed of different national, ethnic, religious, and linguistic groups. About $76 \%$ of its citizens are Jews, $16 \%$ Arab Moslems, $2 \%$ Arab Christians, 1.5\% Druze, and the remaining small minorities or unidentified groups. The majority of the Jewish population immigrated to the country one or two generations ago (ICBS, 2009). Though the country is dominantly secular, its culture is woven with Jewish history and customs, and two thirds of its Jewish population have a strong feeling of Jewish identity (Levy, Levinson, \& Katz, 2002).

\section{Culture as System of Knowledge and Choice}

Culture as a system of knowledge and choice was studied in the past by analyzing the beliefs, commitments, and identities of individuals with a diverse cultural background (Berry, 1988; Birman, 1994; Moghaddam, Taylor, \& Lalonde, 1987; Phinney, 1990). Berry (1988) developed a model specifying four different ways by which immigrants relate to an inter-cultural conflict. These are known as assimilation, separation, marginalization, and integration, and they each specify an identity-related decision and also a way by which cultural knowledge is processed and later manifested.

Another line of work focused on ethnic identities and cultural orientations and has shown that, under some circumstances, individuals can successfully internalize or identify with more than one culture (Benet-Martinez \& Haritatos, 2005; Benet-Martinez, Lee, \& Leu, 2006; Tadmor \& Tetlock, 2006). It has been 
further made evident that this identification may be the result of an automatic and unconscious process (Thierry, 2006).

Other researchers suggested additional ways of viewing culture as a framework of knowledge and choice. Wurzel (1988) presented a cultural worldview he termed Monoculturalism in which familiar manners of interpreting social experience are regarded superior to others and universally valid. According to this conception, foreign forms of thought and action are strange, unsophisticated, unnecessary, and even dangerous. They are therefore rejected and prevented from influencing the prevailing cultural belief system. A different approach is exhibited by Alternation (Hong et al., 2000; LaFromboise, Coleman, \& Gerton, 1993) which is characterized by an effort to acquire at least two different cultural systems. An individual who possesses this cognitive and behavioral framework may feel strong identification with both cultures and will learn to adaptively switch between them and display culture-related repertories in their appropriate contexts (Hong et al., 2000). Finally, Multiculturalism entails an acceptance of different cultural systems, without attributing higher validity to any one of them in particular (Fowers \& Richardson, 1996). This cultural framework, in addition, "... is tolerant of cultural differences, the ambiguities of knowledge, and variations in human perspective" (Wurzel, 1988, p.10). The multicultural person interprets differences that exist between various cultural scenarios as learning opportunities and uses them as catalysts for personal growth.

\section{Cultural Epistemes}

The proposed CEs of the current model were generated using eight epistemological principles that order knowledge in a systematic manner (Medin, 1989). The principles were placed as bipolar dimensions that included the following pairs: 1) Consistency - Inconsistency 2) Fixedness - Dynamics 3) Form preservability - Transformation 4) Singularity - Plurality 5) Context independent - Context dependent 6) Other independent - Other dependent 7) Epistemic Apparatus 8) Choice and commitment. These are all based on fundamental issues regarding the structure of knowledge systems (Bernecker \& Dretske, 2000), but they are not supposed to represent an exhaustive list of epistemic criteria. A broader discussion of the principles, their source, and justification for their use appears elsewhere (Bukobza, 2007).

Each of the eight principles plays a role in the construction of each CE and differences between the CEs depend on the way the principle manifests itself in the episteme. Hence, different types of knowledge systems can be composed with relation to each principle, pending on how that principle is manifested. In order to clarify the relationship between the principles and the epistemes, the four CEs shall be explicated with reference to basic epistemological assumptions and to each of the aforementioned principles. The main differences between the four CEs according to the eight principles are summarized in Table 1. 
Table 1. Differences between the four CEs according to the eight epistemic principles

\begin{tabular}{|c|c|c|c|c|}
\hline $\begin{array}{l}\text { Epistemic } \\
\text { principles }\end{array}$ & $\begin{array}{l}\text { Monoculturalis } \\
\mathrm{m}\end{array}$ & $\begin{array}{l}\text { Pluralistic } \\
\text { relativism }\end{array}$ & $\begin{array}{l}\text { Dialectical } \\
\text { Multiculturalism }\end{array}$ & $\begin{array}{l}\text { Integral } \\
\text { Uniculturalism }\end{array}$ \\
\hline $\begin{array}{l}\text { Consistency - } \\
\text { Inconsistency }\end{array}$ & $\begin{array}{l}\text { Consistent; } \\
\text { negation of } \\
\text { contradictions }\end{array}$ & $\begin{array}{l}\text { Inconsistent; } \\
\text { contradictions } \\
\text { attributed to } \\
\text { relative differences } \\
\text { between systems }\end{array}$ & $\begin{array}{l}\text { Inconsistent; } \\
\text { contradictions are } \\
\text { an internal } \\
\text { condition of any } \\
\text { system }\end{array}$ & $\begin{array}{l}\text { Consistent; } \\
\text { contradictions are } \\
\text { synthesized to } \\
\text { Meta-structure }\end{array}$ \\
\hline $\begin{array}{l}\text { Fixedness - } \\
\text { Dynamics }\end{array}$ & $\begin{array}{l}\text { Fixedness; } \\
\text { elements in the } \\
\text { system are } \\
\text { constant }\end{array}$ & $\begin{array}{l}\text { Dynamics; } \\
\text { dialogue and } \\
\text { reflection bounded } \\
\text { by cultural borders }\end{array}$ & $\begin{array}{l}\text { Dynamics; } \\
\text { dialogue and } \\
\text { reflection } \\
\text { unbounded by } \\
\text { cultural borders }\end{array}$ & $\begin{array}{l}\text { Fixedness; } \\
\text { dynamic elements } \\
\text { contained within } \\
\text { an underlying } \\
\text { constant Meta- } \\
\text { structure }\end{array}$ \\
\hline $\begin{array}{l}\text { Form } \\
\text { preservability - } \\
\text { Transformation }\end{array}$ & $\begin{array}{l}\text { Preservability; } \\
\text { system does not } \\
\text { change }\end{array}$ & $\begin{array}{l}\text { Transformative; } \\
\text { change restricted } \\
\text { to separate } \\
\text { systems }\end{array}$ & $\begin{array}{l}\text { Transformative; } \\
\text { change } \\
\text { unrestricted to } \\
\text { separate systems }\end{array}$ & $\begin{array}{l}\text { Preservability; } \\
\text { changes occur } \\
\text { within an invariant } \\
\text { Meta-structure }\end{array}$ \\
\hline $\begin{array}{l}\text { Singularity - } \\
\text { Plurality }\end{array}$ & $\begin{array}{l}\text { Singularity; } \\
\text { resistance to } \\
\text { multiplicity }\end{array}$ & $\begin{array}{l}\text { Plurality; multiple } \\
\text { separated systems }\end{array}$ & $\begin{array}{l}\text { Plurality; multiple } \\
\text { intertwined } \\
\text { systems }\end{array}$ & $\begin{array}{l}\text { Singularity; } \\
\text { multiple systems } \\
\text { reduced to a single } \\
\text { Meta-structure }\end{array}$ \\
\hline $\begin{array}{l}\text { Context } \\
\text { independent - } \\
\text { Context } \\
\text { dependent }\end{array}$ & $\begin{array}{l}\text { Context } \\
\text { independent; } \\
\text { disregard of } \\
\text { contextual factors }\end{array}$ & $\begin{array}{l}\text { Context } \\
\text { dependent; } \\
\text { contexts are } \\
\text { separated }\end{array}$ & $\begin{array}{l}\text { Context } \\
\text { dependent; } \\
\text { contexts are } \\
\text { interrelated }\end{array}$ & $\begin{array}{l}\text { Context } \\
\text { independent; } \\
\text { various contexts } \\
\text { enveloped by a } \\
\text { non-contextual } \\
\text { Meta-structure }\end{array}$ \\
\hline $\begin{array}{l}\text { Other } \\
\text { independent - } \\
\text { Other } \\
\text { dependent }\end{array}$ & $\begin{array}{l}\text { Other } \\
\text { independent; } \\
\text { disregard of others }\end{array}$ & $\begin{array}{l}\text { Other dependent; } \\
\text { openness to } \\
\text { others within } \\
\text { specific contexts }\end{array}$ & $\begin{array}{l}\text { Other dependent; } \\
\text { openness to } \\
\text { others beyond } \\
\text { specific contexts }\end{array}$ & $\begin{array}{l}\text { Other } \\
\text { independent; other } \\
\text { voices all } \\
\text { interpreted } \\
\text { according to the } \\
\text { Meta-structure }\end{array}$ \\
\hline $\begin{array}{l}\text { Epistemic } \\
\text { Apparatus }\end{array}$ & Limited & $\begin{array}{l}\text { Multiple, non- } \\
\text { traditional, } \\
\text { consistent; in } \\
\text { appropriate } \\
\text { contexts }\end{array}$ & $\begin{array}{l}\text { Multiple, non- } \\
\text { traditional, } \\
\text { inconsistent; not } \\
\text { determined by } \\
\text { context }\end{array}$ & $\begin{array}{l}\text { Limited; multiple } \\
\text { ways are } \\
\text { synthesized }\end{array}$ \\
\hline $\begin{array}{l}\text { Choice and } \\
\text { commitment }\end{array}$ & $\begin{array}{l}\text { Commitment to } \\
\text { mother-culture }\end{array}$ & $\begin{array}{l}\text { Alternation } \\
\text { between contexts }\end{array}$ & $\begin{array}{l}\text { No single } \\
\text { commitment, } \\
\text { juxtaposition of } \\
\text { alternatives }\end{array}$ & $\begin{array}{l}\text { Commitment to a } \\
\text { synthesized Meta- } \\
\text { structure or a } \\
\text { return to mother } \\
\text { culture }\end{array}$ \\
\hline
\end{tabular}




\section{Monoculturalism}

Individuals possessing this CE perceive themselves as belonging exclusively to one cultural group and believe that foreign systems of thinking and behaving are irrelevant and perhaps inferior. In epistemological terms they (1) seek consistency in their framework of knowledge and hence do not accept contradictory views that oppose their own; (2) do not engage in discussions, interactions, or transactions with other cultural sources; (3) oppose attempts to change their prevailing structure of cultural knowledge and choice (4) are singular and exclusive in their cultural beliefs, knowledge, and behavior, and eschew signs of cultural multiplicity; (5) are independent of contextual influences; (6) are independent of other people's cultural beliefs or of interactions with others regarding cultural issues; (7) use only known and established traditional ways of knowing and verifying cultural knowledge; and (8) exhibit an absolute commitment to their original mother-culture and a deterrence of other cultures.

\section{Pluralistic Relativism}

This CE attributes equal value to one's original culture and to foreign cultural forms and belief systems. It shares with other relativistic epistemologies the belief in the legitimacy and truth-value of other knowledge systems and positions itself in relation to them. Individuals possessing this CE (1) accept that inconsistencies could exist in a cultural system and attribute them to relative differences in place, history, social expectations, linguistic frameworks, and the like; (2) engage in ongoing dynamic discussions, interactions, and transactions between cultural systems, though boundaries between systems are kept; (3) welcome change of cultural beliefs and meaning as long as the change is confined and suitable to its specific context; (4) embrace the plurality of the cultural world and the relativity of any cultural position; (5) are very dependent on different contexts; (6) view different cultural interpretations positively and engage in learning from them in their specific contexts; (7) use multiple ways of knowing and verifying cultural knowledge that have meaning in particular contexts; and (8) adopt and enact different cultural aspects such as language, values, rituals, and the like in an alternating fashion pending on contextual factors.

\section{Dialectical Multiculturalism}

This CE emphasizes the existence of contradictory elements in any system, and the perpetual motion and transformation of all systems. It challenges conventional cultural concepts through questions, negations, dialogue, and doubt. Individuals possessing this CE (1) construct a contradiction-ridden cultural framework which sees antinomies within any phenomenon, without trying to 
resolve or contextualize them; (2) are dynamic in their constant reflection and discussion of cultural elements and are not restricted by traditional cultural borders; (3) constantly pursue cultural transformation even if the new formation is incongruent with context; (4) create new forms of multicultural knowledge and choice that go beyond their original context of development; (5) do not perceive cultures to belong to different separated contexts, but see them instead as existing in a complex, intertwined worldwide web of human life and action; (6) constantly interact with other cultural sources regardless of their prescribed contexts; (7) use multiple and often contradictory and out-of-context methods of knowing and verifying cultural knowledge; (8) are not committed to any one cultural choice since they perceive no cultural boundaries, hence enacting a mixture of forms and aspects of cultures.

\section{Integral Uniculturalism}

According to this CE, culture as a system of knowledge has a stable, uniform, and perennial structure. Consequently, the Integral Uniculturalist strives to expose or construct a framework that unites oppositions within and between different cultural occurrences. Individuals possessing this CE (1) develop a consistent $\mathrm{CE}$, not based on rejecting instances of opposition but on synthesizing them into a holistic worldview; (2) perceive any discussion, interaction, or transaction as serving one grand Meta-culture; (3) are unmovable in their cultural knowledge and beliefs since they see them as transcendent and completely valid (4) are singular and exclusive in their cultural beliefs, knowledge, and behavior since they assume that underneath the patina of different cultures people around the world share similar core attributes; (5) are completely independent of contextual factors, since they believe that all contexts share the commonalities of all cultures; (6) are completely independent of other people's views or of interactions with others regarding cultural matters since they conceive their cultural beliefs to envelop all other thoughts and explanations; (7) use known and established traditional ways of knowing that they view as reliable indicators of truth; and (8) exhibit an absolute commitment to one integrative notion and practice of culture.

\section{Method}

\section{Participants}

A total of 80 participants in the study were drawn from four distinct age groups broadly representing the entire adult span. This allowed searching for age differences that could sustain a developmental model in the future. The first two age groups represented the years of emergent adulthood where one's general 
and cultural identity is in its formative stages (Phinney, 1990). The next two groups sampled individuals in mid-life and in the mature adulthood stage. Each group consisted of 20 individuals and was evenly divided by gender. The age groups were 17-22 years ( $\mathrm{M}$ age $=19 \mathrm{yrs}, 11$ months), 26-32 years ( $\mathrm{M}$ age $=28$ yrs, 7 months), 37-47 years ( $\mathrm{M}$ age $=40$ yrs, 4 months) and 56-70 years ( $\mathrm{M}$ age $=59 \mathrm{yrs}, 10$ months). All participants were Jewish Israeli citizens since the study focused on questions relating to this particular culture. Moreover, as this was an exploratory study, choosing a particular cultural group minimized the effect of intervening variables such as language, religion, and nationality. Participants lived in cities, villages, and kibbutzim across Israel. All participants in the study were recruited through social networks from workplaces, educational institutions, and other facilities. They all volunteered to the study and did not receive monetary compensation for their time. Participants were given pseudonyms in order to protect their anonymity during the scoring of the interviews.

\section{Procedures}

The CEs were examined using two cultural dilemmas (see Appendix) that were followed by a semi-structured interview. The dilemmas were presented in the form of ill-structured questions: i.e., they did not have a right or wrong answer and were used mainly as a way to elicit discussion. After having read the first dilemma, the interviewee was asked to give a personal answer and to justify it. The semi-structured interview then followed, examining different aspects of the participant's cultural framework based on the eight principles of order. This process repeated itself with the second dilemma. The author conducted all of the interviews, which took place in either the participant's or author's house, according to the preference of the former. Interviews were recorded and later transcribed. One interviewee asked that the tape recording of his interview be given to him after its transcription, and his request was fulfilled.

Each interview was read as a whole and content analyzed according to each of the eight principles of order. The coder then wrote a brief evaluative summary of how the interviewee performed in terms of each principle so that at the end eight short descriptions were produced. The process can be illustrated with reference to the first principle. The coder in this case had to decide to what degree the participant's framework of culture is consistent or inconsistent and what kind of reasoning is used to explain the level of consistency. While analyzing the interview, guiding questions were used in order to assist the coder in tapping the participant's knowledge and reasoning. In this example the coder asked if there was an awareness of contradictions in the interviewee's framework of cultural knowledge and choice and furthermore what the interviewee's view of these contradictions was if they existed or how their absence was explained if they did not. The coder then supplied an evaluative summary and went on to code the interview according to the next principle. 
The evaluations were used in the next step of the coding process to sort the interview into one of the four CEs in the following manner:

- If six or more of the evaluations fitted into a theoretical description of one of the CEs, it was considered a good fit of that CE.

- Cases with less than six were considered a partial fit and were tagged according to their two most dominant CEs.

The author scored all of the interviews according to the aforementioned method. In addition, two other coders were trained by the author, and they scored half of the interviews. The interviews that were scored independently by the three coders were then discussed in collaboration. Disagreements in scores were resolved in this manner. All coders were blind to age, educational level, or gender of the participants but were aware of the theoretical assumptions of the model. The results of the content analysis were transformed into a scale composed of 13 grades and representing whole and partial CEs using an established method (Perry et al., 1986). Inter-rater reliability between the three coders had an alpha value of $0.72(p<0.005)$.

\section{Results}

Content analysis of the interviews revealed evidence supporting the existence of the four CEs specified by the theoretical model. The Integral Uniculturalism CE appeared in the interviews in two versions that shared the same basic structure but differed in elements of content. This variation was not anticipated in advance and will be presented and explained in the results section. All CEs will be illustrated with examples from the interviews. Note that the interviewees are responding to the dilemmas which initiated the interview but each excerpt is taken from a different part in the interview. Following each excerpt is a short analysis explaining the coding for that particular segment.

\section{Monoculturalism; Moshe, 57 years, male}

Q: Which school would you send your children to in a foreign country?

A: A Jewish school because I want to give them a continuous experience. I want them to keep the things they learned in the past - the holidays, the rituals, the tradition. It's not a matter of obligation but of a choice and will; I want them to be connected to their roots and I want to educate them in light of Jewish values. Other values are good for other people, but for my children I want to give our values alone.

$\mathrm{Q}$ : But why is that so important?

A: I was educated in this manner. I was born in this country to parents who were the last remaining survivors of their families. I was educated in a 
kibbutz. These are my milestones. The holidays, the festivals; they're connected to songs, to ceremonies, to the soul of everyday culture. In my opinion it is all part of a long continuum. And I would like to make myself and my family a part of that historical continuum.

This is an example of a strong commitment to one's original culture and a marked independence from other cultural forms. Moshe presented a solitary conscious preference to the culture to which he belonged and equally had absolutely no interest in others' cultural ways of living. In epistemic terms this CE adhered to a single, homogeneous meaning system that was assumed to be reliable and trustworthy.

\section{Pluralistic Relativism, Paz, 32 years, male}

$\mathrm{Q}$ : Are there any advantages to getting to know a new culture?

A: I think there are many advantages. It's very similar to getting to know a new person. You exchange ideas with him, you see the differences and similarities between you and him and in the end this interaction can bring about a positive change to your life. The same thing happens with a new culture. You encounter something which is very different. You see that things can be done differently than what you're used to at home. You can accept some of these new ways and you can choose to learn and benefit from them. You can also choose to keep away from some of these ways; when you see things in the foreign culture that you perceive as negative, what happens is that your own habits are reinforced and you understand that many of your original cultural attributes were good.

This is an example of being other-dependent and dynamic. Paz's CE viewed different types of culture as equal in value and validity. As a result of this relativistic perspective, he placed his own beliefs in dependent relation to these other cultures and was willing to interact with them and change himself accordingly. Nevertheless, Paz perceived foreign knowledge as belonging to an altogether different context, which is separated from his own. He acknowledged the importance of learning or experiencing other worlds but placed them at a distance from his core cultural system. Some elements from foreign cultures were valued negatively and were rejected.

\section{Dialectic Multiculturalism; Chaim, 27 years, male}

Q: How do you feel about experiencing and learning a new culture?

A: Every culture we can think of has the surface area which is folkloristic and the deeper level which is the essence. I believe that experiencing the deeper essence has huge importance. It is part of what you must learn about this world as a human being. It's part of that which you must possess. It's a wealth, an internal wealth, and it might even have something to do with the goal of achieving happiness. The mystery of Man 
is presented, together with some of its possible solutions, in different ways across the world. I believe that it's preferable that the different ideas shall meet. One idea might be more powerful and convincing than others or they may also exist unresolved in your consciousness. In either case you will know that there are two alternative approaches. Naturally this will ease much burden from many people. It might also create a stimulus or maybe a new pattern of thought, or even a channel that up to now was unfamiliar. This new composition will guide you to places in your mind that you've never visited before.

This CE is characterized by an awareness of cultural contradictions and transformations. Chaim demonstrated a wish to be exposed to different kinds of cultural knowledge, to learn from all, and to transform his own CE accordingly. He did not wish to reconcile between contradictions and was content instead with being aware of their mutual existence. In his opinion they all form a part of the human condition which he strove to be acquainted with.

\section{Integral Uniculturalism Type 1 - Transcendent; Dalit, 27 years, female}

$\mathrm{Q}$ : What is the culture to which you belong?

A: We belong to many circles in our life. One circle of belonging is the family, or local culture, or your religion. And another circle of belonging is the world. The closer the circle is to you, the more time and thought, study and depth you will give to it. But you must never ignore the circle of the world, even if it looks far away. You are still and always will be a son of Earth. A son of your time, and a son of humanity. The final aim I have is to reach a unity. In the end I believe we are all one. We are a multitude, which forms a unity. We need to reduce the multitude into something singular.... And then you realize that everything you see is the fragmentation of that One into thousands of small components that show themselves to you in their multiplicity, sometimes in oppositions and conflict and sometimes not. I understand that these ideas clash with the world of concepts as we know it, but once you live with that unity you merge with all that comes to you and then there is no good and bad and duality but one love for everything.

Dalit interpreted the multitude of elements that make up reality as being the abundant reflection of a deeper unified essence. All human institutions - culture, religion, society, etc. - are inherently united by a governing truth. This is a view that integrates every possible cultural aspect under a single core concept.

Integral Uniculturalism: Type 2 - Particularistic; Zeev, 50 years, male

Q: Which are you more interested in and committed to - your own culture or the other cultures which you've experienced? 
A: If after all you've seen in other cultures and in other countries you still decide to stay committed to your culture, it will become much more meaningful for you. In this case it's not that you happened to be born that way and you just passively carried on with no personal investment. On the contrary, you will now know more about who you are, and you'll be able to deal with yourself better.... I also want to say that tribalism is important to me. I do not see myself as a cosmopolitan. I do not look on things from the outside and say "That's a nice culture and that's a nice culture and everything is the same." There is a point in the end where man connects with himself.... Look, my conception of a good and beautiful world is of a world that is multi-cultural and folkloristic. It is a world where you meet a culture that has a stronghold on its land and that culture develops from its environment. So Man finds his food and his clothing and his shelter in his own environment. When I say multiculturalism I mean that everyone keeps his or her own characteristics. I don't want it to sound like I'm saying that we should seal off our cultures, but the truth is that we must admit that the more attractive things for us come from the isolated and closed-up places. We go to those places because we believe that they have kept their authenticity - we take pictures, we document them, we research them and they're secluded from us! The fact is that Man today - just tell him about a place that locked itself up and kept its traditional ways of work and culture, and he'll run there to see it.

Q: Why will he run to that place?

A: I think it is hope. The Western man - who works hard and saves money and then can travel and get to that society, he is... he's very active but he is also a technocrat, and he goes to the more authentic place out of hope.

This is an example of the second type of the Integral CE. Ze'ev presented a view of culture which acknowledged the rich diversity of cultural options in the world, yet opted to commit to a very specific unitary one. This decision followed from his experiences and encounters with foreign cultures and so didn't stem from a foreclosed adherence to his own culture, as is the case with the Monoculturalist CE. Ze'ev integrated all he knew and learned from other cultures into a unitary concept of what culture should be like. This integrated concept is not a transcendent one like in the previous version of this CE, but rather a local and particularistic one.

Table 2 presents the distribution of the different CEs in the population sample. As can be seen in the table, the majority (87.5\%) of the interviews fitted a single CE. The largest group of participants had a Pluralist Relativistic CE consisting of about half the sample. The rarest CEs were Dialectical Multiculturalism and Integral Uniculturalism which were each presented in a whole or shared form by not more than a fifth of the population. The table shows that there was a high degree of similarity in the frequencies of CEs between women and men. 
Table 2. Distribution of the CEs in the population

\begin{tabular}{lrrr}
\hline & $\begin{array}{r}\text { All Participants } \\
(\mathbf{N}=\mathbf{8 0})\end{array}$ & $\begin{array}{r}\text { Women } \\
(\mathbf{N}=\mathbf{4 0 )}\end{array}$ & $\begin{array}{r}\text { Men } \\
(\mathbf{N}=\mathbf{4 0 )}\end{array}$ \\
\hline Monoculturalism & $20.0 \%$ & $20.0 \%$ & $20.0 \%$ \\
Mono/Plural & $7.5 \%$ & $7.5 \%$ & $7.5 \%$ \\
Pluralistic Relativism & $40.0 \%$ & $42.5 \%$ & $37.5 \%$ \\
Plural/Dialect & $5.0 \%$ & $5.0 \%$ & $5.0 \%$ \\
Dialectical & $12.5 \%$ & $15.0 \%$ & $10.0 \%$ \\
Multiculturalism & & $0 \%$ & $0 \%$ \\
Dialect/Integral & $0 \%$ & $10.0 \%$ & $20.0 \%$ \\
Integral & $15.0 \%$ & & \\
Uniculturalism & & & \\
\hline
\end{tabular}

Table 3. Distribution of the CEs according to the four age groups

\begin{tabular}{lrrrr}
\hline & $\begin{array}{r}\mathbf{1 7 - 2 2} \text { years } \\
\mathbf{( N = 2 0 )}\end{array}$ & $\begin{array}{r}\mathbf{2 6 - 3 2} \text { years } \\
\mathbf{( N = 2 0 )}\end{array}$ & $\begin{array}{r}\mathbf{3 7 - 4 7} \text { years } \\
\mathbf{( N = 2 0 )}\end{array}$ & $\begin{array}{r}\mathbf{5 6 - 7 0} \text { years } \\
(\mathbf{N}=\mathbf{2 0})\end{array}$ \\
\hline Monoculturalism & $25 \%$ & $10 \%$ & $20 \%$ & $25 \%$ \\
Mono/Plural & $10 \%$ & $5 \%$ & $10 \%$ & $5 \%$ \\
Pluralistic Relativism & $65 \%$ & $30 \%$ & $25 \%$ & $40 \%$ \\
Plural/Dialect & $X$ & $15 \%$ & $5 \%$ & $X$ \\
Dialectical Multiculturalism & $X$ & $25 \%$ & $20 \%$ & $5 \%$ \\
Dialect/Integral & $X$ & $X$ & $X$ & $X$ \\
Integral Uniculturalism & $X$ & $15 \%$ & $20 \%$ & $25 \%$ \\
\hline
\end{tabular}

Differences were found between the age groups in the relative proportion of each CE, as shown in table 3 . The youngest age group consisted of only Monoculturalists and Pluralistic Relativists, the latter being the dominant group. In the next two age groups there was a larger variance and at least some representation of each of the CEs. Finally, the oldest group presented a high proportion of Monoculturalists and Pluralistic Relativists similar to the youngest group but additionally consisted of the largest group of Integral Uniculturalists. This suggests that certain CEs are related to age and life experience but are not necessarily actualized by all individuals. 


\section{Discussion}

Studies on ethnic identity, acculturation, and cultural orientation provide evidence to the existence of well-functioning identities composed of several cultural systems (Benet-Martı'nez, Lee, \& Leu, 2006; Hong et al., 2000). Hong et al. (2000) illustrated, for instance, the process of cultural frame switching (CSF) in which a person is highly competent in two different cultural contexts. According to the present research this and more complex abilities are determined by the type of CE a person possesses.

The latter assertion can be illustrated in relation to multiculturalism as a worldview (Fowers \& Richardson, 1996; Wurzel, 1988). The present model differentiated between two kinds of epistemes that represent and fulfill a multiple perspective of culture. The first, Pluralistic Relativism, represents most bicultural identities and CSF abilities. This CE acknowledges the validity of several cultural systems and responds adaptively to changing cultural cues within their specific contexts. The maintenance of such a CE could reduce instances of ambiguity or anxiety that occur as a result of life within a diverse cultural system. The second kind, Dialectical Multicultural, has the added complexity of activating cultural elements beyond their original location. Unlike the pluralistic relativist, the dialectical multiculturalist is not bound by contextual factors and is able to transfer meanings between different settings, as well as to respond to internal contradictions and changes within a specific setting. This CE may be more suitable in explaining diasporic identities which negotiate between a conflicting polyphony of values, beliefs, and cultural practices (Bhatia, 2002) and is a more apt representation of identities and orientations found among people living in the perplexing conditions of late modernity (Giddens, 1991).

The CE is further associated with behavior. Having a certain organization of cultural knowledge could be related to one's intentions to act. Thus, a person who holds a Monocultural CE will experience conflict when values and practices of his or her culture are incompatible with those of others. Encounters with other forms of culture could be met with suspicion, deterrence, and in some cases aggressive opposition by the monoculturalist. Such behavioral implications have direct consequences to multicultural education as one of its goals is the advancement of positive intergroup meetings. Whether the particularistic or pluralistic educational approach is embraced (Reingold, 2007), the intergroup contact could largely depend on the type of CE participants have. For example, having two groups of mainly Monocultural individuals may prove hazardous to the success of such an encounter since the epistemic gap will be too far to bridge. Alternatively, Pluralistic Relativists and Dialectical Multiculturalists may be more open to encounters with others as their initial episteme construes the social world in open terms. The former group, however, may still be more reluctant to change following such contact because its CE tends to localize different cultural elements in specified disconnected contexts. The dialectical CE on the other hand specializes in creating inter-contextual meanings and therefore could reap 
the fruits of such encounters. It may prove beneficial therefore to examine individuals' and groups' CE profiles as part of the group contact process. In a later stage it may be reasonable to enhance thinking along the more open CEs before the beginning of such meeting.

Further educational purposes that can be advanced by using the current model can be accomplished in higher education and teacher education settings. Learning about the different ways by which individuals hold and organize cultural knowledge and preferences may assist the understanding of issues such as cultural identities, cultural attitudes, and inter group relations on several levels. First, the model emphasizes the basic four mental frameworks that support different cultural attitudes, beliefs, and choices. In a similar way to how we learn about human universal properties (Stork, 2008), acknowledging the existence of these fundamental structures may shed light on issues relating to the human cultural condition. Second, it has been suggested that the epistemes follow a developmental sequence (Bukobza, 2008). Hence, the model could be used as a framework for educational interventions which encourage CE transformations along the suggested trajectory.

The processes of immigration, acculturation, and cultural conflict may serve as another example to the practicality of the current model. According to Berry (1988) immigrants choose whether to acquire new cultural experience or otherwise remain committed to their original cultural world. Similarly, Tadmor and Tetlock (2006) claim that individuals who cope with cultural conflict can choose whether to adhere to one cultural solution or alternatively internalize the values of more than one group. Results of the present study suggest that the ability to accommodate cultural differences, demands, and tensions is related to the type of CE available. Berry's depictions of separation and assimilation, for example, could be conceived as particular cases of a Monocultural CE that constructs a unitary, coherent framework that negates external cultural knowledge. Such a CE is inclined to conform to the approved form of a single doctrine, and its choices are thus restricted to singular cultural options.

The present research exposed a variety of CEs, and this has particular consequences to governmental and educational institutions which interact with minority populations. The acknowledgement that such variability exists within any group can assist counselors, psychologists, officials, and other professionals to better structure the support they extend to individuals and families from these groups. Indeed the actual environments created by organizations and individuals in such cases should take into account the variability of CEs, which characterizes the target audiences. It should additionally be taken into consideration that the diversity of the CEs may complicate interactions between individuals, especially if there is no awareness that the diversity exists. Since people are guided by the way they make sense of the world, a conflict could result between individuals espousing opposing CEs because they relate differently to cultural issues. For example, a teacher could hold on to a Monocultural CE when the students in the class could gain more from a Pluralistic Relativist perspective. In more extreme examples an impasse can result in inter-group negotiations if the two sides 
possess contradictory CEs. Such scenarios may repeat in contexts of intercultural exchange, relations, businesses, cooperation, debates, and the like. Awareness and knowledge of the diverse cultural frameworks may contribute to a better management of these situations and to the resolution of potential conflicts (Salinas, 2007).

The distribution of the CEs in the study varied with age: The youngest age group consisted only of Monocultural and Pluralistic Relativist CEs. In contrast, in the older age groups a significant proportion of the population presented Dialectical Multicultural and Integral Uniculturalism CEs. These results suggest that certain epistemes are related to individuals' life experiences. Moreover, the different CEs could be distinguished from one another according to their level of epistemic complexity (Bukobza, 2007; Roccas \& Brewer, 2002; Tadmor \& Tetlock, 2006) with Monoculturalism being the least and Integral Uniculturalism the most complex. This implies that an association exists between a person's age and life experience and the level of complexity that characterizes his or her cultural framework. However, these are not sufficient factors since only a minority of the older participants exhibited more advanced forms of CE. Further research is needed to determine the variables and conditions that contribute to the development of more complex CEs. Research on advanced modes of conceptualizations (Kegan, 1982) suggests that a challenging but secure environment and the pursuit of higher education may be related to such progress.

\section{Recommendations for Further Study}

A caveat in the study was the use of eight specific principles to guide the analysis of the interviews. Although these principles were the product of thorough investigation and theoretical grounding (Bukobza, 2007), they cannot escape the claim that the use of alternative principles could have potentially yielded different CEs. Further work will therefore have to be carried out in order to establish the validity of the different CEs and the methods by which they were measured. A related limit is the cultural context in which this study was carried out. All of the participants in the study came from one dominant culture, and it remains to be seen for generalization purposes how relevant the present model is to other cultures, as well as to members of immigrant and minority groups. Research with additional cultural groups will allow a replication of the CEs identified and provide a useful case of comparison. 


\section{References}

Banks, J. (1993). The canon debate, knowledge construction, and multicultural education. Education Researcher, 22(5), 4-14.

Benet-Martinez, V., \& Haritatos, J. (2005). Bicultural identity integration (BII): Components and psychosocial antecedents. Journal of Personality, 73(4), 1015-1050.

Benet-Martinez, V., Lee, F., \& Leu, J. (2006). Biculturalism and cognitive complexity: Expertise in cultural representations. Journal of Cross Cultural Psychology. 37(4), 386-407.

Bernecker, S., \& Dretske, F. (2000). Knowledge: Readings in contemporary epistemology. Oxford: University Press.

Berry, J. W. (1988). Acculturation and psychological adaptation: A conceptual overview. In J. W. Berry, \& R. C. Annis (Eds.), Ethnic psychology: Research and practice with immigrants, refugees, native peoples, ethnic groups and sojourners (pp. 41-52). Amsterdam: Swets \& Zeitlinger.

Bhatia, S. (2002). Acculturation, dialogical voices and the construction of the diasporic self. Theory \& Psychology, 12(1), 55-77.

Birman, D. (1994). Acculturation and human diversity in a multicultural society. In E. J. Trickett, R. J. Watts and D. Birman, (Eds.) Human diversity: Perspectives on people in context (pp. 261-284). San Francisco: JosseyBass.

Bruner, J. S. (2008). Culture and mind: Their fruitful incommensurability. Ethos, 36(1), 29-45.

Bukobza, G. (2007). The epistemological basis of selfhood. New Ideas in Psychology, 25(1), 37-65.

Bukobza, G. (2008). The development of knowledge structures in adulthood. In P. N. Blakely, \& A. H. Tomlin (Eds.), Adult education: Issues and developments (pp. 175-204). New York: Nova Science.

Foucault, M. (1970). The order of things: An archeology of the human sciences. New York: Pantheon Books. (Original published 1966).

Fowers, W. B., \& Richardson, F. C. (1996). Why is multiculturalism good? American Psychologist, 51(6), 609-621.

Giddens, A. (1991) Modernity and self-identity: Self and society in the late modern age. Cambridge, MA: Polity Press.

Hong, Y. Y., Morris, M., Chiu, C. Y., \& Benet-Martinez, V. (2000). Multicultural minds: A dynamic constructivist approach to culture and cognition. American Psychologist, 55(7), 709-720. 
Israel Central Bureau of Statistics (2009). Retrieved May 12, 2009, from http://www.cbs.gov.il/publications/isr in n08e.pdf

Kegan, R. (1982). The evolving self: Problem and process in human development. Cambridge, MA: Harvard University Press.

Kelley, G. A. (1955). The psychology of personal constructs, Vol. 1. New York: Norton.

LaFromboise, T., Coleman, H. L. K., \& Gerton, J. (1993). Psychological impact of biculturalism: Evidence and theory. Psychological Bulletin, 114(3), 395412.

Levy, S., Levinson, H., \& Katz, E. (2002). Beliefs, tradition, and values of the Jewish population in Israel in the year 2000. Jerusalem: The Louis Guttman Israel Institute of Applied Social Research. (Hebrew).

Medin, D. L. (1989). Concepts and conceptual structure. American Psychologist, 44(12), 1469-1481.

Moghaddam, F. M., Taylor, D. M., \& Lalonde, R. N. (1987). Individualistic and collective integration strategies among Iranians in Canada. International Journal of Psychology, 22(3), 301-313.

Perry, B., Donovan, M. P., Kelsey, L. J., Paterson, J., Statkiewicz, W., \& Allen, R. D. (1986). Two schemes of intellectual development: A comparison of development as defined by William Perry and Jean Piaget. Journal of Research in Science Teaching, 23(1), 73-83.

Phinney, J. S. (1990). Ethnic identity in adolescents and adults: Review of research. Psychological Bulletin, 108(3), 499-514.

Reingold, R. (2007). Promoting a true pluralistic dialogue: A particularistic multicultural teacher accreditation program for Israeli Bedouins. International Journal of Multicultural Education, 9(1), 1-14.

Roccas, S., \& Brewer, M. B. (2002). Social identity complexity. Personality and Social Psychology Review, 6(2), 88-106.

Salinas, M. F. (2007). Planting hatred, sowing pain: The psychology of the Israeli Palestinian conflict. Westport, CT: Greenwood/Praeger.

Siegel, H. (2006). Epistemological diversity and education research: Much ado about nothing much? Education Researcher, 35(2), 3-12.

Stork, E. (2008). Using human universals to teach multicultural perspectives. International journal of multicultural education, 10(1), 1-10.

Tadmor, C. T., \& Tetlock, P. E. (2006). Biculturalism: A model of the effects of second-culture exposure on acculturation and integrative complexity. Journal of Cross Cultural Psychology, 37(2), 173-190.

Thierry, D. (2006). Implicit bicultural identity among Mexican American and Asian American college students. Cultural Diversity and Ethnic Minority Psychology, 12(3), 381-402. 
Wurzel, J. S. (1988). Toward multiculturalism: A reader in multicultural education. Yarmouth, ME: Intercultural Press.

\section{Appendix}

The following are the two cultural dilemmas used in the study:

1) Family abroad

A Jewish-Israeli family has moved from Israel to the United States for a period of four years, after which they plan to return to their homeland. The parents are debating whether to send their six-year-old daughter to an American public school, or instead to an Israeli oriented Jewish school which teaches in Hebrew.

Where do you think should the parents send their child? why?

2) Curriculum

The ministry of education is interested in adding ten more hours to the weekly school curriculum. It has been decided that the added classes will be devoted to the study of cultures. There are five possible cultural systems the new program can focus on:

Jewish culture and values; European culture and values; Arab culture and values; North American culture and values; and South East Asian culture and values.

It is possible to divide the prescribed time between more than one system (e.g. 5 hours to a certain program, 3 to a second, and 2 to a third), or to devote all available hours to one program.

How do you think should the time be allocated? For what reasons? 